\title{
Validation of the Swedish version of the Pain Catastrophizing Scale for Parents (PCS-P) for parents of children with cancer
}

This article was published in the following Dove Medical Press journal: Journal of Pain Research

\author{
Jenny Thorsell Cederberg' \\ Sandra Weineland ${ }^{2,3}$ \\ JoAnne Dahl ${ }^{4}$ \\ Gustaf Ljungman'
}

'Department of Women's and Children's Health, Uppsala University, Uppsala, Sweden; ${ }^{2}$ Research and Development Center, Primary Health Care, Region Västra Götaland, Sweden; ${ }^{3}$ Department of Psychology, University of Gothenburg, Göteborg, Sweden; ${ }^{4}$ Department of Psychology, Uppsala University, Uppsala, Sweden
Correspondence: Jenny Thorsell Cederberg

Department of Women's and Children's Health, Uppsala University, Uppsala University Hospital, SE-75I 85 Uppsala, Sweden

Tel +46 I8 508680

$\mathrm{Fax}+46186110197$

Email jenny.thorsell.cederberg@kbh.uu.se
Objectives: Pain is reported as one of the most common and burdensome symptoms for children with cancer. Pain catastrophizing is clearly related to pain intensity and disability. Catastrophizing in parents is associated with both child functioning and parent distress. The Pain Catastrophizing Scale for Parents (PCS-P) remains to be validated for parents of children with cancer. The aim of the study was to validate the Swedish version of the PCS-P for parents of children with cancer experiencing pain.

Methods: Parents of all children who were being treated for cancer in Sweden at the time of the study were invited to participate. Study material was sent out to the registered address. Internal consistency, test-retest reliability, and convergent validity were calculated, and factor analysis was conducted. Descriptive statistics was used to investigate the background data and norm values. Results: A total of 243 parents participated in the study. The results did not support the original three-factor structure of the PCS-P, but rather suggested that a two-factor structure best represented the data. The results showed excellent internal consistency ( $\alpha=0.93)$, excellent temporal stability (intraclass correlation coefficient $=0.86$ ) and moderate convergent validity $(\rho=0.57)$. The mean (SD) for the PCS-P in the sample was 28.3 (10.7). A statistically significant difference was found between mothers and fathers, where mothers reported a higher level of pain catastrophizing than fathers.

Conclusion: The psychometric properties of the PCS-P has now been supported in a sample of parents of children with cancer, and norm values are now available. The factor structure does, however, deserve more investigation.

Keywords: The Pain Catastrophizing Scale for Parents (PCS-P), validation, parents, cancer, pain

\section{Introduction}

Children and adolescents with cancer report pain as one of the most frequent and burdensome adverse symptoms throughout their cancer trajectory. ${ }^{1}$ The pain is generally caused by the disease itself, side effects of cancer treatment, and/or medical procedures. ${ }^{2,3}$ In pain research, the interconnection between pain and emotions has become increasingly clear. Pain and emotions constantly influence each other neurophysiologically, and the relationship is reciprocal. ${ }^{4,5}$ This means that pain does not only cause psychological distress but that psychological distress also amplifies the nerve transmission of pain impulses. ${ }^{6-8}$ In neuro-imaging studies, positive emotions have been shown to neurologically inhibit pain impulses, while negative emotions have been shown to facilitate them. ${ }^{9}$ Furthermore, if the pain is perceived as a threat, pain impulses are neuro-physiologically amplified. ${ }^{10}$ In line with this, pain catastrophizing 
is a highly influential process of pain. ${ }^{11}$ Pain catastrophizing refers to the process where pain is interpreted as being very threatening. ${ }^{12}$ It can be conceptualized as the cognitive component of fear ${ }^{13}$ and infers an inability to shift one's attention away from pain. ${ }^{14,15}$ Pain catastrophizing is associated with disability in both pain patients ${ }^{16-19}$ and the general population. ${ }^{20}$ In accordance with the reciprocity between pain and emotions, pain catastrophizing is further related to intensified pain. ${ }^{10,21-27}$ The Pain Catastrophizing Scale (PCS) ${ }^{28}$ was developed in 1995 and has been widely used since and validated in numerous languages. ${ }^{29-39}$ The PCS consists of 13 items and comprises three subscales measuring different features of pain catastrophizing: rumination, magnification, and helplessness. The rumination subscale consists of four items measuring ruminative thoughts and an inability to impede pain-related thoughts. The magnification subscale reflects intensification of the unpleasantness of pain and expectancy of negative outcomes. The helplessness subscale reflects an inability to cope with the pain. The PCS has shown good internal consistency and temporal stability and correlates with measures of psychological distress, functional disability, and pain intensity. ${ }^{24,25,28,40}$ Parents' pain catastrophizing has been shown to be associated with child pain intensity, functional disability, emotional functioning, and parental distress and behavior. ${ }^{41-46}$ The parent version of the PCS, the PCS for parents (PCS-P) was developed in $2006 .{ }^{47}$ The psychometric properties of the scale and the three-factor model of the original version were supported. The three-factor structure has been supported in two other studies, by Hechler et $\mathrm{al}^{67}$ in 2010 and Frerker et $\mathrm{al}^{68}$ in 2018. However, in one study, by Pielech et al in 2014, an 11-item two-factor model was recommended. ${ }^{48}$ In summary, the psychometric properties of the PCS-P have been supported in community and chronic pain samples. The factor structure and number of items does, however, deserve more attention. Validated measures enable the investigation of processes of change in different populations. This in turn facilitates the optimization of treatments. In the context of cancer, pain may be interpreted as particularly threatening and in which pain catastrophizing may play an even more pronounced role. Validation of the PCS in the context of cancer is therefore of great importance. Furthermore, considering the relationship between parental catastrophizing and child distress and functioning, validation of the PCS-P for parents of children with cancer is significant.

\section{Aim}

The aim of the study was to validate the Swedish version of the PCS-P in a sample of parents of children with cancer, with regard to factor structure, internal consistency, test-retest reliability, convergent validity, and norm values.

\section{Methods}

\section{Participants and procedures}

The current study was part of a larger project for which the overall aim was to develop and evaluate psychological interventions to help children with cancer to cope with the pain that is often associated with undergoing cancer treatment. As part of this aim, scales for measuring psychological flexibility in relation to pain, often called pain acceptance, were developed, for children with cancer ${ }^{49}$ and their parents. ${ }^{50}$ The PCS-P was used as a validation measure for the parent scale.

Parents of all children (0-18 years) undergoing cancer treatment in Sweden at the time of the study were invited to participate. The Swedish Childhood Cancer Registry identified 485 eligible patients. Patient data was insufficient for one child; hence, he/she was excluded. The research nurses at the six pediatric oncology centers in Sweden were consulted to double-check that neither of the identified patients had gone into palliation or died after data withdrawal, in order to ensure that the parents of these children were not contacted. One child was identified as undergoing palliation, and he/she was therefore excluded. Parents of 483 children were contacted, via mail, and invited to participate in the study. The study material consisted of information about the study, questions on background information, the test version of the scale under development (the Pain Flexibility Scale for Parents ${ }^{50}$ ), evaluation questions, and two validation measures, of which the PCS-P was one. Parents were offered to be included in a lottery of movie tickets for participating in the study. Consent was given through participation in the study. Upon no reply, a reminder was sent out 2 weeks after the first dispatch. For the purpose of test-retest analysis, the test material was sent out again 1 month after the collection of the first measurement. No patient information was present on the study material, rather a code was used to identify the participants. The code key was only accessible to the first author of the study. Two hundred and forty six parents participated in the study, of 160 children. A hundred and seventeen parents participated in both the measurements and 129 participated at only one measurement. Data from three parents were excluded due to incorrect completion of the measures. Two hundred and forty three participants were included in the analyses. Nine dispatches were returned by the Postal Service. No response was received from parents of 205 children and 25 parents (of 23 children) declined. Two test-retest measurements were received 8 months after data collection closure and were not 
included in the study. The study was approved by the Regional Ethical Review Board in Uppsala, Sweden (Dnr 2014/375).

\section{Background information}

Background information included relationship to the child, age and gender of the child, type and date of diagnosis, date of end of treatment (if applicable), type of pain, and ratings of pain and discomfort of pain. The ratings were made on a Numerical Rating Scale (NRS) from $0=$ "No pain/discomfort at all" to $10=$ "Unbearably lot of pain/discomfort" ${ }^{\text {"51 }}$ and covered current and highest, lowest and average level of pain during the past week, as well as current and average level of discomfort of pain during the past week.

\section{The PCS-P}

The PCS-P measures catastrophizing thoughts in parents of children in pain. ${ }^{47}$ It consists of 13 items starting "When my child is in pain....”. The specific items are presented in Table 1. Respondents rate their agreement with the statement on a 5-point Likert scale. Score range is 0-52 and higher scores indicate a higher level of catastrophizing. The scale consists of three subscales. The rumination subscale is made up by items $8,9,10$, and 11 ; the magnification subscale by items 6,7 , and 13; and the helplessness subscale by items $1,2,3,4,5$, and 12. Cronbach's alpha has been shown to be $a=0.81-0.93$, and the scale has been shown to correlate with child pain intensity, functional disability, emotional functioning, and parental distress and behavior. ${ }^{41-46} \mathrm{~A}$ Swedish version of the PCS-P was used.

\section{Measure for validation}

Due to the aim of the larger study, to develop a scale for measuring psychological flexibility in relation to pain in parents of children with cancer, the Acceptance and Action Questionnaire (AAQ-II) was used to assess convergent validity. The AAQ-II measures a general level of experiential avoidance. ${ }^{52,53}$ Experiential avoidance is defined as "unwillingness to remain in contact with aversive private experiences followed by behavioral responses to avoid, alter or otherwise control those aversive experiences." ${ }^{54}$ It has been proposed to be a trans-diagnostic factor ${ }^{52,55}$ and to constitute a generalized vulnerability for psychopathology. ${ }^{56}$ Experiential avoidance and pain catastrophizing have been shown to be related but unique constructs. ${ }^{57}$ Participants rate their agreement with statements such as "I'm afraid of my feelings" and "I worry about not being able to control my worries and feelings," on a 7-point Likert scale. Higher scores indicate a higher level of experiential avoidance. Cronbach's alpha for the AAQ-II has been shown to be $\alpha=0.78-0.88$, test-retest reliability over 3 months has been shown to be 0.81 , and the scale correlates with a range of measures of mental health. The Swedish AAQ (SAAQ) short version of six items was used, ${ }^{58}$ which has shown good internal consistency $(\alpha=0.85)$, temporal stability ( $r=0.80)$, good concurrent, and convergent validity and for which a one-factor structure has been supported. The psychometric properties of this version were examined in the larger project of the study and supported for the sample. ${ }^{59}$

\section{Statistical analyses}

All statistical analyses were performed in IBM SPSS Statistics, version $24 .{ }^{60}$ Given the question marks regarding number of factors and items as well as the novel sample in the current study, principal component analysis (PCA) was conducted to investigate factor-structure. The sample size was adequate, inter-item correlation coefficients were mainly above 0.30 , Bartlett's test of sphericity was significant and the Kaiser-

Table I Factors, items, factor loadings, and communalities of a two-factor solution with Promax rotation for the PCS-P

\begin{tabular}{|c|c|c|c|}
\hline Factor & $\begin{array}{l}\text { Item } \\
\text { When my child is in pain... }\end{array}$ & Factor loading & Communality \\
\hline I & $\begin{array}{l}3 \ldots \text { it's terrible and I think it's never going to get better } \\
5 \ldots \text { I can't stand it anymore } \\
2 \ldots \text { I feel I can't go on like this much longer } \\
7 \ldots \text { I keep thinking of other painful events } \\
4 \ldots \text { it's awful and I feel that it overwhelms me } \\
\text { I .. I I worry all the time about whether the pain will end } \\
6 \ldots \text { I become afraid that the pain will get worse } \\
\text { I3 ... I wonder whether something serious may happen } \\
12 \ldots \text { there is nothing I can do to stop the pain }\end{array}$ & $\begin{array}{l}0.965 \\
0.892 \\
0.870 \\
0.700 \\
0.665 \\
0.660 \\
0.651 \\
0.514 \\
0.502\end{array}$ & $\begin{array}{l}0.616 \\
0.625 \\
0.558 \\
0.355 \\
0.724 \\
0.629 \\
0.675 \\
0.519 \\
0.237\end{array}$ \\
\hline 2 & $\begin{array}{l}8 \ldots \text { I want the pain to go away } \\
\text { II .. I keep thinking about how much I want the pain to stop } \\
10 \ldots \text { I keep thinking about how much he/she is suffering } \\
9 \ldots \text { I can't keep it out of my mind }\end{array}$ & $\begin{array}{l}0.997 \\
0.799 \\
0.738 \\
0.562\end{array}$ & $\begin{array}{l}0.274 \\
0.518 \\
0.662 \\
0.647\end{array}$ \\
\hline
\end{tabular}

Abbreviation: PCS-P, the Pain Catastrophizing Scale for Parents. 
Meyer-Olkin index was 0.94, supporting the suitability for factor analysis. ${ }^{61}$ The Kaiser's criterion and the scree plot were assessed to determine the number of factors to extract. Interdependence between the factors was highly indicated, and hence, oblique rotation was used. Cronbach's alpha was calculated to assess internal consistency. The intraclass correlation coefficient (ICC) was calculated to assess possible dependence in scores between pairs (ie, parents of the same child) and test-retest reliability. ${ }^{62,63}$ A two-way random model assessing the single measures value was used. ${ }^{64} \mathrm{An}$ ICC value of $<0.40$ indicates poor inter-rater agreement, between 0.40 and 0.59 fair, between 0.60 and 0.74 good, and $>0.75$ excellent. ${ }^{65}$ Regarding possible dependence between pairs, the ICC was 0.293 for absolute agreement and 0.397 for consistency, showing low dependence between pairs. Correlation with the SAAQ was performed to assess convergent validity. The data on neither of the scales were normally distributed, and hence, Spearman's rho correlation was used. Correlation coefficients were interpreted according to guidelines, ${ }^{66}$ with $\rho=0-0.19$ very weak, $0.20-0.39$ weak, $0.40-0.59$ moderate, $0.60-0.79$ strong, and $0.8-1.0$ very strong. Descriptive statistics were used to investigate background data and to calculate norm values. Mann-Whitney $U$ test was conducted to compare the scores between mothers and fathers.

\section{Results}

\section{Descriptive analysis}

Out of the 243 participants included in the analyses, 147 were mothers and 96 fathers. The mean (SD) age of the children was 7.5 (5.1) years, with a range from 0 to 18 years. Fifty six percent of the children were boys and $44 \%$ were girls. Regarding diagnoses of the children, 51\% had leukemia, $36 \%$ had solid tumor, and $13 \%$ had brain tumor. The means (SD) of the parents' reports of the children's current and average level of pain during the last week were 1.30 (1.93) and 1.43 (1.80), respectively. The mean (SD) of the current and average level of discomfort of pain during the last week were 1.25 (1.85) and 1.58 (2.05), respectively.

\section{Factor analysis}

The PCA yielded two factors with eigenvalues above 1, explaining $54.1 \%$ and $8.5 \%$ of the variance, respectively. The scree plot showed a very distinct break after the first factor. Hence, the Kaiser's criterion and the scree plot yielded different results with regard to number of factors to retain. In the preliminary analysis, communalities were all above 0.3 except for item 12, which had a communality value of 0.255 . Based on the scree plot, forcing a one-factor solution yielded lower communalities and factor loadings on average. Therefore, a two-factor solution was considered to best represent the data. The Promax rotation yielded higher factor loadings. The results for this solution are presented in Table 1.

\section{Reliability and convergent validity}

Cronbach's alpha for the PCS-P was $\alpha=0.93$, which indicates excellent internal consistency. The ICC test-retest correlation coefficient was 0.86 , indicating excellent temporal stability. The Spearman's rho coefficient for the correlation with the SAAQ was $\rho=0.57$, indicating a moderate correlation.

\section{Norm values}

Mean, SD, SE, CI for mean, trimmed mean, median, and score range for the PCS-P in the sample are presented in Table 2. The mean (SD) for mothers was 29.4 (10.5) and for fathers 26.7 (10.9), a statistically significant difference (Sig. 44 000, "Reject the null hypothesis").

\section{Discussion}

The aim of the study was to validate the Swedish version of the PCS-P for parents of children with cancer. The original three-factor model of the PCS-P was not supported by the results, which showed that a two-factor model fitted the data best. This is in line with the results from Pielech et al. ${ }^{48}$ The Pielech et $\mathrm{al}^{48}$ study did, however, recommend an 11-item model. The two items recommended for removal were items 7 and 8 . In the current study, both factor loading and communality were adequate for item 7. Although the communality value was low for item 8 , the factor loading was quite high (0.997). Taken together, the results did not find support for removing any items of the 13-item model. Factor 1 in our study was composed by the six items from the helplessness subscale and the three items from the magnification subscale. Factor 2 was composed by the four items of the rumination subscale. Hence, the original factors

Table 2 Mean, SD, SE, Cl for mean, trimmed mean, median, and score range for the PCS-P in the sample

\begin{tabular}{|l|l|l|l|l|l|l|}
\hline The PCS-P & Mean (SD) & SE & $\mathbf{9 5 \%}$ Cl for mean & $\mathbf{5 \%}$ trimmed mean & Median & Score range \\
\hline Total scale, I3 items & $28.3(10.7)$ & 0.7 & $27.0-29.7$ & 28.3 & 29.0 & $0-52$ \\
\hline
\end{tabular}

Abbreviation: PCS-P, the Pain Catastrophizing Scale for Parents. 
were, in that manner, stable apart from the merging of the helplessness and the magnification subscales. In that way, one could conclude that the factors yielded in the current study still represents the same underlying concepts as in the original studies. Whether a two- or a three-factor model of the PCS-P is best needs to be investigated further, particularly in the pediatric cancer population. The psychometric properties of the PCS-P, with regard to internal consistency, temporal stability, and convergent validity, were supported. The internal consistency and test-retest reliability were excellent. The correlation with the SAAQ was moderate, which was expected given that the two concepts are related but distinct. The mean (SD) in our sample was 28.3 (10.7). In the original PCS-P study, ${ }^{47}$ the mean (SD) was found to be 15.7 (9.9) in parents of healthy children and 29.5 (11.2) in parents of children with chronic pain. The mean found in our study does indeed seem to represent a clinical sample. One could assume, however, that parents of children with cancer would catastrophize to a higher extent about their child's pain than parents of children with non-malignant chronic pain. The slightly lower mean in our sample may be explained by a lower level of pain in the children. The mean (SD) current pain intensity was 1.30 (1.93) for the children in our sample and 5.33 (3.09) for the children in the reference sample. There was a statistically significant difference between mothers and fathers, where mothers reported a higher level of catastrophizing. A difference in this direction has been reported previously. ${ }^{67}$ Women have been shown to report higher levels of catastrophizing not only in relation to their child's pain but also in general. ${ }^{28} \mathrm{At}$ the time, the reason for this observed difference remains an empirical question.

Parents of all children who were being treated for cancer in Sweden at the time of the study were invited to participate in the study. There was no control question regarding current or previous pain, which is a limitation of the study. This may have inferred that parents of children who had not experienced pain participated in the study. This risk is, however, considered small. First, the patient information stated that the study addressed parents of children with cancer experiencing pain. Second, pain is reported as one of the most frequent adverse symptoms for children with cancer ${ }^{1}$ and is likely to affect all children with cancer, to some extent, at one time or another. Current pain was not necessitated, and the parents were able to report retroactively about their experience during their child's pain. This may have affected their reports. Seeing one's child in pain is generally a very stressful experience for a parent, and possibly particularly for a parent of a child with cancer. One could speculate that such an experience would linger in one's consciousness, and in that way reduce the risk of memory bias. Nevertheless, retroactive reports are never ideal and constitutes a limitation of the study. Parents of a third of the children participated in the study. This response rate is considered realistic given the challenging situation for these families, the format of the study with having to fill in questionnaires, and the common proportion of respondents in survey research today. With regard to generalizability of the results, this should, however, be kept in mind. The Swedish version of the PCS-P was used. This version has been available for years and used frequently but has not been validated in previous studies. In order to assess if and how this version differs from the original version in any cultural or linguistic aspect, it should be validated in equivalent samples as well. Pain catastrophizing in parents is associated with pain intensity, functional disability, and emotional functioning in the child and distress in the parent. Validated instruments and population-specific norm values enable identifying patients, or parents in this case, likely to benefit from preventive and therapeutic interventions. The psychometric properties have now been supported, and norm values have been made available for the PCS-P for parents of children with cancer. This may facilitate the process of providing the right interventions for these parents during a challenging life situation, seeing one's child sick and in pain. This is likely to benefit both the parent and the child. The factor structure of the PCS-P does, however, deserve more attention.

\section{Acknowledgments}

We would like to thank the Swedish Childhood Cancer Registry for identifying participants and the research nurses of the pediatric oncology centers in Sweden for screening the patient list. We would also like to acknowledge the Swedish Childhood Cancer Fund and the Swedish Cancer Society for funding. Lastly, we would like to thank our participants for taking the time to fill out the questionnaires. This work was supported by grants from the Swedish Childhood Cancer Foundation (PR2013-0058) and the Swedish Cancer Society (CAN2013/749).

\section{Disclosure}

The authors report no conflicts of interest in this work.

\section{References}

1. Twycross A, Parker R, Williams A, Gibson F. Cancer-related pain and pain management: sources, prevalence, and the experiences of children and parents. J Pediatr Oncol Nurs. 2015;32(6):369-384. 
2. International Association for the Study of Pain (IASP) [webpage on the Internet]. 2008-2009 Global Year Against Cancer Pain. Available from: http://www.iasp-pain.org/GlobalYear/CancerPain. Accessed November $1,2018$.

3. Ljungman G, Kreuger A, Gordh T, Berg T, Sörensen S, Rawal N. Treatment of pain in pediatric oncology: a Swedish nationwide survey. Pain. 1996;68(2-3):385-394.

4. Linton SJ. Understanding Pain for Better Clinical Practice: A Psychological Perspective. Edinburgh: Elsevier; 2005.

5. Linton SJ, Shaw WS. Impact of psychological factors in the experience of pain. Phys Ther. 2011;91(5):700-711.

6. Wiech K, Ploner M, Tracey I. Neurocognitive aspects of pain perception. Trends Cogn Sci. 2008;12(8):306-313.

7. Wiech K, Tracey I. The influence of negative emotions on pain: behavioral effects and neural mechanisms. Neuroimage. 2009;47(3): 987-994.

8. Tracey I. Getting the pain you expect: mechanisms of placebo, nocebo and reappraisal effects in humans. Nat Med. 2010;16(11):1277-1283.

9. Denk F, Mcmahon SB, Tracey I. Pain vulnerability: a neurobiological perspective. Nat Neurosci. 2014;17(2):192-200.

10. Zale EL, Lange KL, Fields SA, Ditre JW. The relation between pain-related fear and disability: a meta-analysis. J Pain. 2013;14(10):1019-1030.

11. Chaves JF, Brown JM. Spontaneous cognitive strategies for the control of clinical pain and stress. J Behav Med. 1987;10(3):263-276.

12. Rosenstiel AK, Keefe FJ. The use of coping strategies in chronic low back pain patients: relationship to patient characteristics and current adjustment. Pain. 1983;17(1):33-44.

13. Leeuw M, Goossens ME, Linton SJ, Crombez G, Boersma K, Vlaeyen JW. The fear-avoidance model of musculoskeletal pain: current state of scientific evidence. J Behav Med. 2007;30(1):77-94.

14. Crombez G, Eccleston C, Baeyens F, Eelen P. When somatic information threatens, catastrophic thinking enhances attentional interference. Pain. 1998b;75(2-3):187-198.

15. Crombez G, Eccleston C, Baeyens F, Eelen P. Attentional disruption is enhanced by the threat of pain. Behav Res Ther. 1998;36(2): 195-204.

16. Turner JA, Jensen MP, Romano JM. Do beliefs, coping, and catastrophizing independently predict functioning in patients with chronic pain? Pain. 2000;85(1):115-125.

17. Turner JA, Jensen MP, Warms CA, Cardenas DD. Catastrophizing is associated with pain intensity, psychological distress, and pain-related disability among individuals with chronic pain after spinal cord injury. Pain. 2002;98(1-2):127-134.

18. Turner JA, Mancl L, Aaron LA. Pain-related catastrophizing: a daily process study. Pain. 2004;110(1-2):103-111.

19. Severeijns R, Vlaeyen JW, van den Hout MA, Weber WE. Pain catastrophizing predicts pain intensity, disability, and psychological distress independent of the level of physical impairment. Clin J Pain. 2001;17(2):165-172.

20. Severeijns R, van den Hout MA, Vlaeyen JW. The causal status of pain catastrophizing: an experimental test with healthy participants. Eur $J$ Pain. 2005;9(3):257-265.

21. Peters ML, Vlaeyen JW, Weber WE. The joint contribution of physical pathology, pain-related fear and catastrophizing to chronic back pain disability. Pain. 2005;113(1-2):45-50.

22. Buer N, Linton SJ. Fear-avoidance beliefs and catastrophizing: occurrence and risk factor in back pain and ADL in the general population. Pain. 2002;99(3):485-491.

23. Haythornthwaite JA, Clark MR, Pappagallo M, Raja SN. Pain coping strategies play a role in the persistence of pain in post-herpetic neuralgia. Pain. 2003;106(3):453-460.

24. Vervoort T, Goubert L, Vandenbossche H, van Aken S, Matthys D, Crombez G. Child's and parents' catastrophizing about pain is associated with procedural fear in children: a study in children with diabetes and their mothers. Psychol Rep. 2011;109(3):879-895.

25. Edwards RR, Cahalan C, Calahan C, Mensing G, Smith M, Haythornthwaite JA. Pain, catastrophizing, and depression in the rheumatic diseases. Nat Rev Rheumatol. 2011;7(4):216-224.
26. Khan RS, Ahmed K, Blakeway E, et al. Catastrophizing: a predictive factor for postoperative pain. Am J Surg. 2011;201(1):122-131.

27. Pinto PR, Mcintyre T, Almeida A, Araújo-Soares V. The mediating role of pain catastrophizing in the relationship between presurgical anxiety and acute postsurgical pain after hysterectomy. Pain. 2012;153(1):218-226.

28. Sullivan MJL, Bishop SR, Pivik J. The pain catastrophizing scale: development and validation. Psychol Assess. 1995;7(4):524-532.

29. Meyer K, Sprott H, Mannion AF. Cross-cultural adaptation, reliability, and validity of the German version of the pain catastrophizing scale. $J$ Psychosom Res. 2008;64(5):469-478.

30. Miró J, Nieto R, Huguet A. The Catalan version of the pain catastrophizing scale: a useful instrument to assess catastrophic thinking in whiplash patients. J Pain. 2008;9(5):397-406.

31. Yap JC, Lau J, Chen PP, et al. Validation of the Chinese pain catastrophizing scale (HK-PCS) in patients with chronic pain. Pain Med. 2008;9(2):186-195.

32. Fernandes L, Storheim K, Lochting I, Grotle M. Cross-cultural adaptation and validation of the Norwegian pain catastrophizing scale in patients with low back pain. BMC Musculoskelet Disord. 2012;13(1):111-111.

33. Sehn F, Chachamovich E, Vidor LP, et al. Cross-cultural adaptation and validation of the Brazilian Portuguese version of the pain catastrophizing scale. Pain Med. 2012;13(11):1425-1435.

34. Morris LD, Grimmer-Somers KA, Louw QA, Sullivan MJ. Crosscultural adaptation and validation of the South African pain catastrophizing scale (SA-PCS) among patients with fibromyalgia. Health Qual Life Outcomes. 2012;10(1):137-137.

35. Cho S, Kim HY, Lee JH. Validation of the Korean version of the pain catastrophizing scale in patients with chronic non-cancer pain. Qual Life Res. 2013;22(7):1767-1772.

36. Mohd Din FH, Hoe VC, Chan CK, Muslan MA. Cultural adaptation and psychometric assessment of pain catastrophizing scale among young healthy Malay-speaking adults in military settings. Qual Life Res. 2015;24(5):1275-1280.

37. Ilçin N, Gürpınar B, Bayraktar D, et al. Cross-cultural adaptation and validation of the Turkish version of the pain catastrophizing scale among patients with ankylosing spondylitis. JPhys Ther Sci. 2016;28(1):298-303.

38. Bansal D, Gudala K, Lavudiya S, Ghai B, Arora P. Translation, adaptation, and validation of Hindi version of the pain catastrophizing scale in patients with chronic low back pain for use in India. Pain Med. 2016;17(10):1848-1858.

39. Huijer HA-S, Fares S, French DJ. The development and psychometric validation of an Arabic-Language version of the pain catastrophizing scale. Pain Res Manag. 2017;2017:1-7.

40. Engel JM, Wilson S, Tran ST, Jensen MP, Ciol MA. Pain catastrophizing in youths with physical disabilities and chronic pain. J Pediatr Psychol. 2013;38(2):192-201.

41. Cunningham NR, Lynch-Jordan A, Barnett K, et al. Child pain catastrophizing mediates the relation between parent responses to pain and disability in youth with functional abdominal pain. J Pediatr Gastroenterol Nutr. 2014;59(6):732-738.

42. Durand H, Birnie KA, Noel M, et al. State versus trait: validating state assessment of child and parental catastrophic thinking about children's acute pain. J Pain. 2017;18(4):385-395.

43. Pagé MG, Campbell F, Isaac L, Stinson J, Katz J. Parental risk factors for the development of pediatric acute and chronic postsurgical pain: a longitudinal study. J Pain Res. 2013;6:727-741.

44. Goldstein-Leever A, Cohen LL, Dampier C, Sil S. Parent pain catastrophizing predicts child depressive symptoms in youth with sickle cell disease. Pediatr Blood Cancer. 2018;65(7):e27027.

45. Sil S, Dampier C, Cohen LL. Pediatric sickle cell disease and parent and child Catastrophizing. J Pain. 2016;17(9):963-971.

46. Caes L, Vervoort T, Eccleston C, Vandenhende M, Goubert L. Parental catastrophizing about child's pain and its relationship with activity restriction: the mediating role of parental distress. Pain. 2011;152(1):212-222.

47. Goubert L, Eccleston C, Vervoort T, Jordan A, Crombez G. Parental catastrophizing about their child's pain. the parent version of the pain catastrophizing scale (PCS-P): a preliminary validation. Pain. 2006;123(3):254-263. 
48. Pielech M, Ryan M, Logan D, Kaczynski K, White MT, Simons LE. Pain catastrophizing in children with chronic pain and their parents: proposed clinical reference points and reexamination of the pain catastrophizing scale measure. Pain. 2014;155(11):2360-2367.

49. Thorsell Cederberg J, Weineland Strandskov S, Dahl J, Ljungman G. Children's and adolescents' relationship to pain during cancer treatment: a preliminary validation of the pain flexibility scale for children. J Pain Res. 2017;10:1171-1178.

50. Thorsell Cederberg J, Weineland Strandskov S, Dahl J, Ljungman G. Parents' relationship to pain during cancer treatment - a preliminary validation of the Pain Flexibility Scale for parents (PFS-P) of children with cancer. J Pain Res. 2017;10:507-514.

51. Ferreira-Valente MA, Pais-Ribeiro JL, Jensen MP. Validity of four pain intensity rating scales. Pain. 2011;152(10):2399-2404.

52. Hayes SC, Strosahl K, Wilson KG, et al. Measuring experiential avoidance: a preliminary test of a working model. Psychol Rec. 2004;54(4): 553-578.

53. Bond FW, Hayes SC, Baer RA, et al. Preliminary psychometric properties of the acceptance and action Questionnaire-II: a revised measure of psychological inflexibility and experiential avoidance. Behav Ther. 2011;42(4):676-688.

54. Hayes SC, Wilson KG, Gifford EV, Follette VM, Strosahl K. Experimental avoidance and behavioral disorders: a functional dimensional approach to diagnosis and treatment. J Consult Clin Psychol. 1996;64(6):1152-1168.

55. Spinhoven P, Drost J, de Rooij M, van Hemert AM, Penninx BW. A longitudinal study of experiential avoidance in emotional disorders. Behav Ther. 2014;45(6):840-850.

56. Kashdan TB, Barrios V, Forsyth JP, Steger MF. Experiential avoidance as a generalized psychological vulnerability: comparisons with coping and emotion regulation strategies. Behav Res Ther. 2006;44(9):1301-1320.

57. Elvery N, Jensen MP, Ehde DM, Day MA. Pain catastrophizing, Mindfulness, and pain acceptance: what's the difference? Clin J Pain. 2017;33(6):485-495.
58. Lundgren T, Parling T. Swedish acceptance and action questionnaire (SAAQ): a psychometric evaluation. Cogn Behav Ther 2017;46(4):315-326.

59. Cederberg JT, Weineland S, Dahl J, Ljungman G. Validation of the Swedish acceptance and action questionnaire (SAAQ) for parents of children with cancer. J Context Behav Sci. 2018;10:50-54.

60. IBM. SPSS Statistics. Version 24.0.0. Armonk: IBM Corporation; 2016.

61. Pallant J. SPSS Survival Manual: A Step by Step Guide to Data Analysis Using IBM SPSS. 6th ed. Maidenhead: Open University Press; 2016.

62. Terwee CB, Bot SD, de Boer MR, et al. Quality criteria were proposed for measurement properties of health status questionnaires. J Clin Epidemiol. 2007;60(1):34-42.

63. Weir JP. Quantifying test-retest reliability using the intraclass correlation coefficient and the SeM. J Strength Cond Res. 2005;19(1) 231-240.

64. Landers R [webpage on the Internet]. Computing Intraclass Correlations (ICC) as Estimates of Interrater Reliability in SPSS. Available from: https://thewinnower.com/papers/1113-computing-intraclasscorrelations-icc-as-estimates-of-interrater-reliability-in-spss. Accessed November 1, 2018.

65. Cicchetti DV. Guidelines, criteria, and rules of thumb for evaluating normed and standardized assessment instruments in Psychology. Psychological Assessment. 1994;6(4):284-290.

66. Cohen J. Statistical Power Analysis for the Behavioral Sciences. 2nd ed. Hillsdale: L. Erlbaum Associates; 1988.

67. Hechler T, Vervoort T, Hamann M, et al. Parental catastrophizing about their child's chronic pain: are mothers and fathers different? Eur J Pain. 2010;15(5):e511-e519.

68. Frerker MK, Hirschfeld G, Thielsch MT, Hechler T. Parental responses to children's pain: Analysis of the parental responses to their child's pain in the German general population. Schmerz. 2018;32(6):434-441.
Journal of Pain Research

\section{Publish your work in this journal}

The Journal of Pain Research is an international, peer reviewed, open access, online journal that welcomes laboratory and clinical findings in the fields of pain research and the prevention and management of pain. Original research, reviews, symposium reports, hypothesis formation and commentaries are all considered for publication.

\section{Dovepress}

The manuscript management system is completely online and includes a very quick and fair peer-review system, which is all easy to use. Visit http://www.dovepress.com/testimonials.php to read real quotes from published authors. 